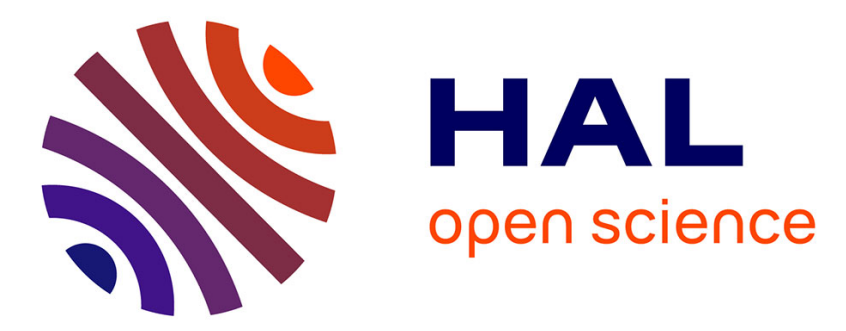

\title{
High-accuracy optical measurement of flatness for large objects
}

S. Pavageau, Richard Dallier, Noël Servagent, T. Bosch

\section{To cite this version:}

S. Pavageau, Richard Dallier, Noël Servagent, T. Bosch. High-accuracy optical measurement of flatness for large objects. Measurement Science and Technology, 2003, 14, pp.2121-2126. 10.1088/09570233/14/12/011 . in2p3-00025261

\section{HAL Id: in2p3-00025261 https://hal.in2p3.fr/in2p3-00025261}

Submitted on 21 Dec 2005

HAL is a multi-disciplinary open access archive for the deposit and dissemination of scientific research documents, whether they are published or not. The documents may come from teaching and research institutions in France or abroad, or from public or private research centers.
L'archive ouverte pluridisciplinaire HAL, est destinée au dépôt et à la diffusion de documents scientifiques de niveau recherche, publiés ou non, émanant des établissements d'enseignement et de recherche français ou étrangers, des laboratoires publics ou privés. 


\title{
High-accuracy optical measurement of flatness for large objects
}

\author{
S Pavageau ${ }^{1}, R_{\text {Dallier }}{ }^{1}, N_{\text {Servagent }}{ }^{1}$ and $T$ Bosch $^{2}$ \\ ${ }^{1}$ Ecole des Mines de Nantes, 4, rue Alfred Kastler, BP 20722, 44307 Nantes cedex 3, France \\ ${ }^{2}$ ENSEEIHT-LEN7, Laboratoire d'Electronique, 2 rue Charles Camichel, BP 7122, \\ 31071 Toulouse cedex 7, France
}

\begin{abstract}
A high-accuracy non-contact optomechanical system has been designed for measuring the surface profile of relatively flat and large objects. The experimental set-up consists of a motorized gantry, a rangefinder, a CCD chip and a laser diode. This set-up permits discrete measurements to be performed on objects with a maximum plane surface area of $2.6 \times 0.5 \mathrm{~m}^{2}$ along both the $X$ and $Y$ axes. Experiments were carried out on carbon sandwich panels. An uncertainty of $\pm 8 \mu \mathrm{m}$ has been obtained on flat and smooth surfaces; $\mathrm{a} \pm 30 \mu \mathrm{m}$ uncertainty has been determined for a rough carbon sandwich panel.
\end{abstract}

Keywords: shape measurement, laser sensor, non-destructive testing

\section{Introduction}

This paper describes an alternative method of shape measurement for large and relatively flat objects. This application forms part of an important stage of a wider project (ALICE), dedicated to fundamental research in particle physics [1]. It requires the building of a large detector system, the structural elements of which are carbon sandwich panels. Controlling the flatness of these large panels $(2450 \mathrm{~mm} \times$ $450 \mathrm{~mm}$ ) is thus essential.

Several methods exist for object profile measurements. For instance optical techniques [2] such as holographic interferometry [3], shearography [4], moiré topography [5, 6] or the fringe projection method [7] are widely used. These techniques permit non-contact, full-field measurements and fast data acquisition but provide high accuracy only for small objects.

In parallel, numerous papers have also been published on high-accuracy measurement of large optical surfaces $(>1 \mathrm{~m}$ in diameter). In most cases, a contact probe $[8,9]$ or optical probe $[10,11]$ is used. As an example, systems have been developed to measure the shape of x-ray telescope mirrors [10] or of the flat table of a machine tool [12].

However, the cost of current surface profiling sensors, whether optically or non-optically based, is prohibitive. To overcome this constraint we have therefore decided to develop our own profilometer to meet our measurement requirements with various user-defined parameters. In this paper we present the description of a 3D measuring system of relatively low cost with a high resolution over the entire measured surface. The application of our set-up has been demonstrated on a $2450 \mathrm{~mm} \times 450 \mathrm{~mm}$ carbon panel.

\section{Experimental set-up}

\subsection{System description}

The experimental set-up consists of a motorized gantry, built to our specifications in our laboratory and customized for profiling relatively flat surfaces. Each axis of the gantry is controlled by a step motor via an individual cable. This setup permits measurements to be performed on objects with a maximum plane surface area of $2.6 \times 0.5 \mathrm{~m}^{2}$ along both the $X$ and $Y$ axes. On the vertical rail, a mechanical fixture has been added to allow both a laser triangulation rangefinder and a CCD chip to be held rigidly. The schematic diagram of the system is given in figure 1 . The carbon panels have to be held vertically in order to overcome the problem of deformation under their own weight. Each panel is thus placed vertically, parallel to the $X$-axis, and is held in place by a simple suction system.

At each $(X, Y)$ displacement along the carbon panel, the absolute distance between the plate and the rangefinder is first 


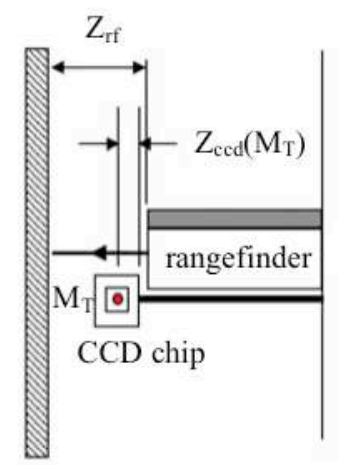

object

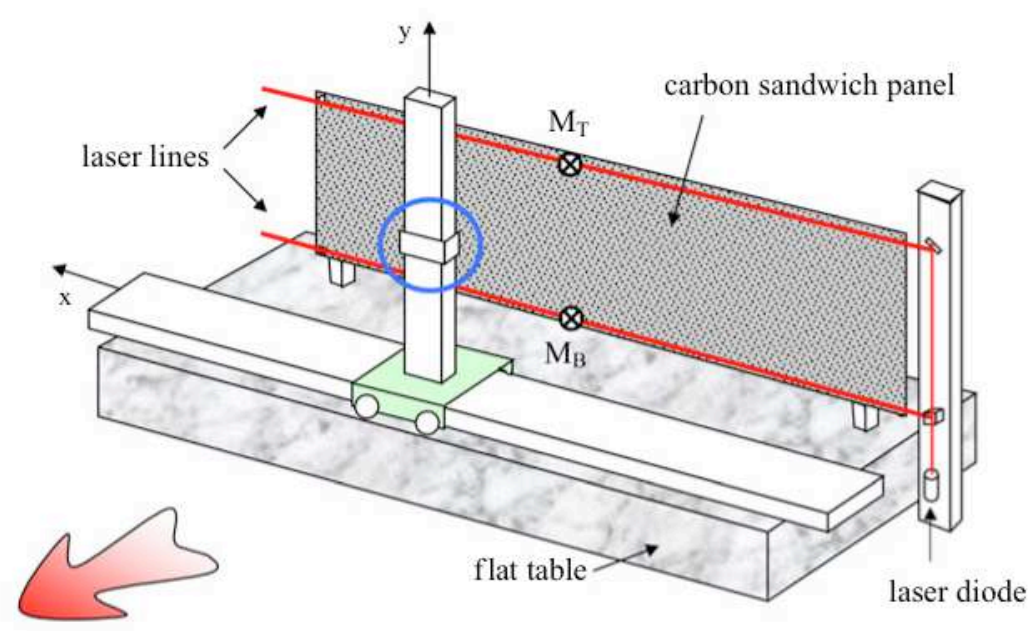

Figure 1. Schematic of the experimental set-up. measured by the rangefinder. This direct measurement is, however, not sufficient to determine the object profile since it uses the displacement along the $X$ rail as a mechanical reference. Although the maximum curvature of the $X$ rail has been measured to be within $200 \mu \mathrm{m}$, an uncertainty of $\pm 30 \mu \mathrm{m}$ is required on such large surfaces. The use of this mechanical reference ( $X$-rail displacement) as flatness data is, thus, not appropriate as it is impossible to know the exact position of this fixture during measurements. The measurement must be calibrated from an external reference plane. We thus designed a calibration system to correct these errors.

\subsection{Calibration}

Initially, a reference plane, exploiting a laser plane generator, was introduced vertically between the gantry and the panel. The rangefinder is displaced in front of the surface to be measured. Its position is monitored relative to the reference laser plane by the use of a CCD chip, which intercepts this plane. The height of each point is then calculated as

$$
Z=Z_{\mathrm{rf}}-Z_{\mathrm{CCD}}
$$

where $Z_{\mathrm{rf}}$ and $Z_{\mathrm{CCD}}$ are the rangefinder measurement and the laser plane position on the CCD chip, respectively. A surface profile can thus be obtained in this way.

Although the use of an internal laser reference plane seemed to be a very simple solution to the reference problem, it was later found that the laser plane was finally not so flat. The laser line generator employed was a commercial, high-precision model, consisting of a prismatic optical head illuminated by a laser diode spot. Measurements with this laser line led to erroneous results. A thorough investigation revealed two phenomena: optical distortion due to the prismatic head, which bends the beam, and, moreover, some interference fringes which modify the transverse intensity profile of the beam at several locations.

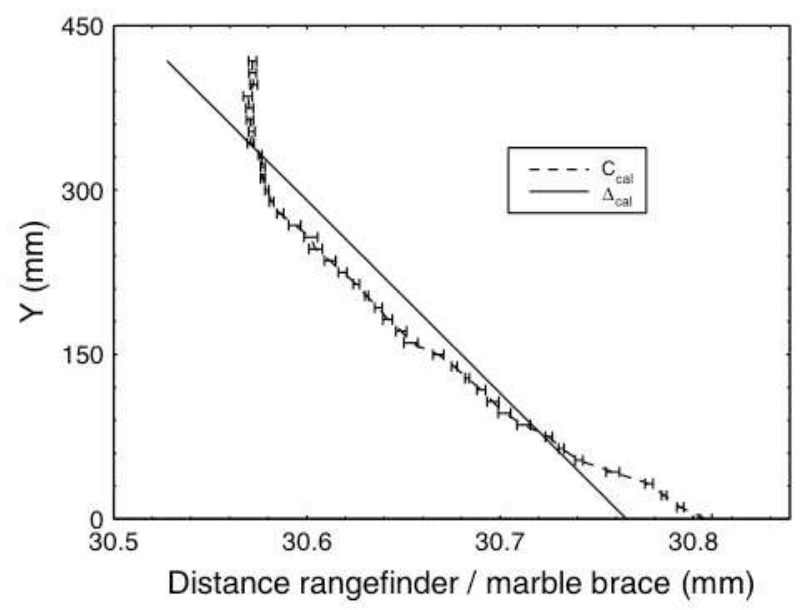

Figure 2. $Y$-axis calibration curve.

We therefore designed another reference plane, based on the use of a high-precision vertical mechanical rail. A calibration of the fixture displacement along this vertical rail enables us to obtain a highly reproducible displacement. In order to obtain this slightly curved movement (which is defined as $C_{\text {cal }}$ ) along the $Y$-axis, approximately 50 measurements have been realized on the same reference surface (high-precision marble brace, $50 \mathrm{~cm}$ high, quoted flatness $\pm 2 \mu \mathrm{m}$ ). Figure 2 represents the mean experimental curve and the standard deviation (of $\sim 4 \mu \mathrm{m}$ ) associated with these measurements and the best-fit linear regression over measurements $\Delta_{\text {cal }}$. The maximum bending has been found to be $60 \mu \mathrm{m}$. Moreover, tests have been realized (over 6 months) to check the validity of the calibration curve and the stability of our set-up. Taking into account the displacement consideration, we then conceived a reference plane based on the use of a twin laser line.

This reference plane consists of a laser diode, with anamorphic beam-conditioning optics, emitting in the visible 


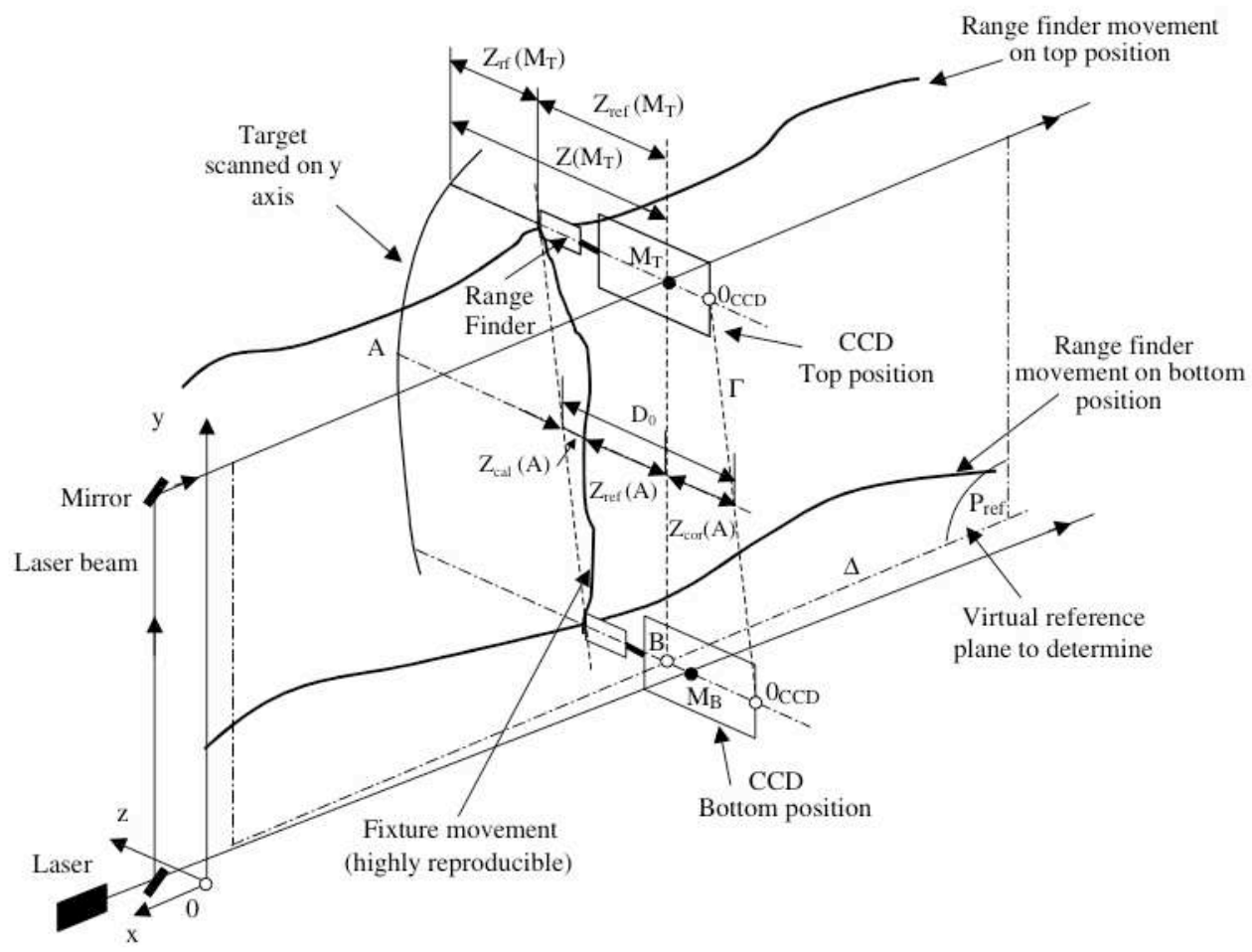

Figure 3. Geometrical description of the set-up.

( $\lambda=670 \mathrm{~nm}, P=1 \mathrm{~mW}$ ) and a CCD chip derived from a commercial webcam. The CCD chip is firmly maintained in the vicinity of the head of the rangefinder but orthogonal to the laser direction of the rangefinder, i.e. in a direction parallel to the object's surface. The diode laser beam is split into two horizontal parallel beams and projected lengthwise across the top and bottom ends of the panel (see figure 1). When the fixture is translated vertically across the panel, the CCD chip intercepts the lower and higher beams, and the corresponding positions are recorded. By translating horizontally along the length of the plate, the whole $X-Y$ displacement plane can then be reconstructed by linking the top and bottom positions of the laser lines through the $Y$ mechanical calibration curve as described in the previous paragraph. To obtain the profile of the object surface, we can then simply subtract this virtual reference plane from the rangefinder measurements.

\subsection{Data processing}

2.3.1. Distance measurement. The triangulation rangefinder has a measuring range of $\pm 5 \mathrm{~mm}$, an accuracy of $20 \mu \mathrm{m}$ and a resolution of $1 \mu \mathrm{m}$. It delivers a voltage directly proportional to the measured distance. The choice of the rangefinder, i.e. a rangefinder with the smallest measuring range, has been done considering the fact that accuracy increases when the full scale measurement range decreases.

Consequently, with the use of such a rangefinder our set-up allows measurements only on relatively flat objects, of which the maximum permissible deformation must be less than $1 \mathrm{~cm}$.

2.3.2. Laser position on the CCD chip. During the vertical displacement of the fixture (see figure 1), the CCD chip intercepts the two laser lines, thus recording their transverse intensity profile. For each interception, the real Gaussian intensity profile is recorded by the CCD. A program, written in Labview ${ }^{\circledR}$, allows the determination of the characteristics of the real signal (height and full width at half-maximum (FWHM) or $\sigma$ ). An ideal Gaussian profile is next generated using the same characteristics as the real signal. The position of the CCD chip (and hence that of the rangefinder, except for a constant $D_{0}$ ) with respect to the laser plane can then be deduced from the cross-correlation product between the two signals. If $\mathrm{M}_{\mathrm{T}}$ (respectively $\mathrm{M}_{\mathrm{B}}$ ) is the point of intersection between the top laser beam (respectively bottom) and the CCD, then the position corresponding to the distance between the edge of the CCD and the laser spot will be denoted $Z_{\mathrm{CCD}}\left(\mathrm{M}_{\mathrm{T}}\right)$ (respectively $Z_{\mathrm{CCD}}\left(\mathrm{M}_{\mathrm{B}}\right)$ ). According to the algorithm used, the laser beam position measured by the CCD is given with an uncertainty better than $1 / 10$ of a pixel. However, an investigation into the stability of the laser beam has shown a variation of the beam position of approximately one pixel over repeated measurements over a few minutes. A reading error of one pixel $(8 \mu \mathrm{m})$ is thus estimated. This can be considered as a stability estimation for one measurement taking into account the overall thermal drifts, mechanical vibration and other disturbances.

2.3.3. Reference plane. Figure 3 shows a geometric description of the set-up.

As previously mentioned, the displacements along the $X$ and $Y$ rails are not perfect. Some corrections must be added to the data from the rangefinder to obtain the real surface profile of the panel and then its flatness.

For this purpose, the two parallel laser beams are situated at the top and bottom end of the panel. Best-fit linear regressions are calculated for the two curves of fixture 
displacement along the $X$ rail, associated with the two laser beams (top and bottom position). Then, we subtract from the bottom curve its best-fit linear regression and add to the resulting curve the best-fit linear regression of the top curve. With this correction, the point $\mathrm{M}_{\mathrm{B}}$ becomes $\mathrm{B}$. The two resulting curves, passing through $\mathrm{M}_{\mathrm{T}}$ and $\mathrm{B}$, create a perfect virtual reference plane $P_{\text {ref }}$.

It should be noted that it does not matter if this virtual plane is difficult to locate spatially as the flatness measurement is only a relative measurement.

The positioning of the beams and their adjustment for parallelism have been checked mechanically, with a maximal error of $\pm 0.5 \mathrm{~mm}$ along $2400 \mathrm{~mm}$, i.e. an angular deviation of about $10^{-2} \mathrm{deg}$. This influence of such an error on the surface profile measurement is of secondary importance compared with the accuracy of the rangefinder $(20 \mu \mathrm{m})$. As a matter of fact, the angular deviation between the two beams leads to a projection error (during the creation of the reference plane) which can be estimated to only one-hundredth of a micrometre.

The surface profile of the object is then deduced from the subtraction between the rangefinder data and the reference plane for each $(X, Y)$ recorded point:

$$
Z=Z_{\mathrm{rf}}-Z_{\mathrm{ref}}
$$

where $Z_{\mathrm{rf}}$ is the distance between the rangefinder and the object, given directly by the rangefinder, $Z_{\mathrm{ref}}$ is the distance between the rangefinder and the reference plane data, to be determined. In the experimental configuration, $Z_{\text {ref }}<0$. For any point $\mathrm{A}, Z_{\mathrm{ref}}$ is given by:

$$
Z_{\text {ref }}=D_{0}-Z_{\text {cor }}-Z_{\text {cal }}
$$

where $D_{0}$ is a constant mechanical distance (distance between $\mathrm{CCD}$ edge and the rangefinder). Exact knowledge of $D_{0}$ is not necessary since we realize relative measurements. $Z_{\text {cor }}$ is the distance between the reference plane (passing through $\mathrm{M}_{\mathrm{T}}$ and B) and the straight line passing through the origin of the $\mathrm{CCD}$ reference in the top and bottom position. The straight line represents the global slope of the vertical rail compared with the reference plane. For each $X$ coordinate, the straight line is calculated from the pair of points $\left(\mathrm{M}_{\mathrm{T}}, \mathrm{M}_{\mathrm{B}}\right)$.

$Z_{\text {cal }}$ is the curve resulting from the subtraction between the rangefinder calibration curve along the $Y$-axis and its best-fit linear regression (figure 2):

$$
Z_{\mathrm{cal}}=C_{\mathrm{cal}}-\Delta_{\mathrm{cal}}
$$

\section{Results and discussion}

Photographs of the operational system, built in our laboratory, are shown in figure 4 . The vertical rail and fixture displacements, as well as the acquisition of rangefinder and CCD chip data, are entirely automated and controlled by a

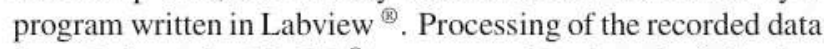
is carried out via a Matlab ${ }^{\circledR}$ program and leads to the following important results: surface profile and flatness criterion.

The flatness criterion is directly derived from the profile map. Flatness is defined as the maximum distance between two perfect, parallel reference planes between which is placed the surface of interest. In order to guarantee relatively acceptable

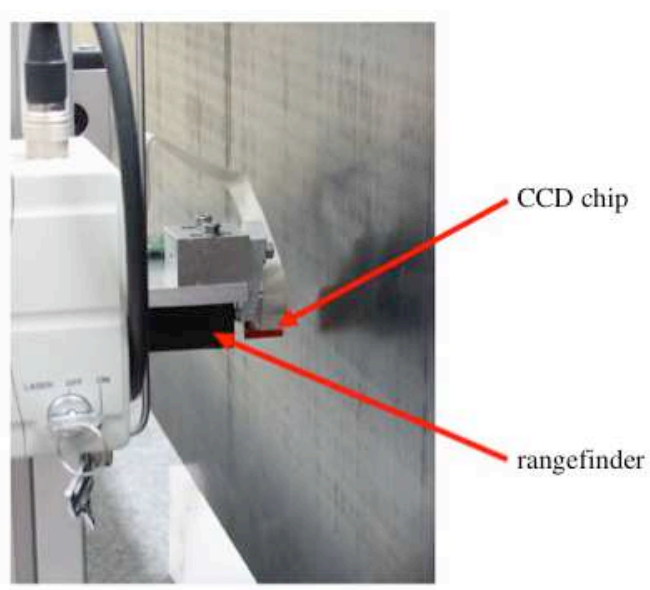

(a)

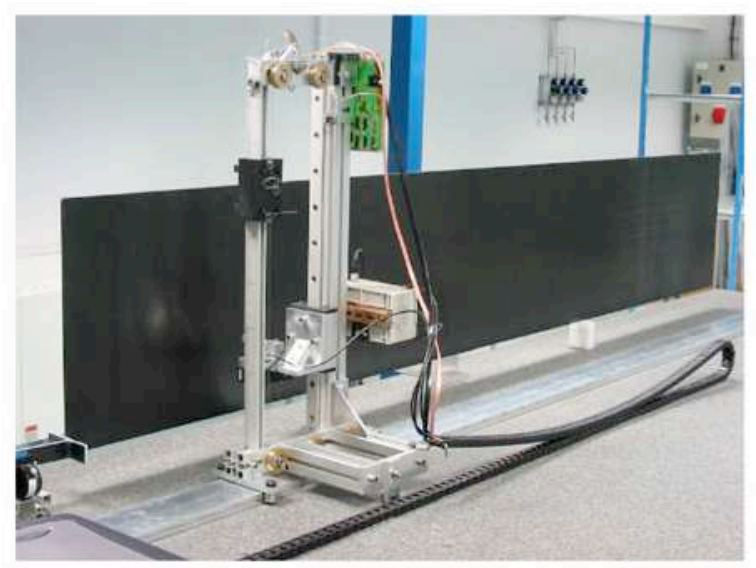

(b)

Figure 4. Photographs of the set-up: (a) lateral view, (b) global view.

results from the whole fundamental experiment of the ALICE project, and according to a conventional mechanical standard abacus, the flatness of these panels must be better than $150 \mu \mathrm{m} \mathrm{m}^{-1}$. The uncertainty of our profile mapping system has therefore been experimentally obtained at $\pm 30 \mu \mathrm{m}$ on the measured height of each point of the surface in order to achieve the overall flatness measurement uncertainty.

Preliminary experiments were carried out on carbon sandwich panels of dimension $2450 \mathrm{~mm} \times 450 \mathrm{~mm}$. Each panel is black and has a diffusive surface. As the laser rangefinder spot is $50 \mu \mathrm{m}$ in diameter, the state of roughness of the object surface is not important if the surface granularity is lower than the spot diameter-which is the case for carbon panels. Figure 5(a) shows the $3 \mathrm{D}$ contour map of a $2450 \mathrm{~mm} \times$ $450 \mathrm{~mm}$ carbon panel. A relatively significant curvature along the $X$-axis can be observed. The calculated flatness is approximately $400 \mu \mathrm{m} \mathrm{m}^{-1}$, which is higher than the required tolerance. In fact, all the tests realized on $2450 \mathrm{~mm} \times 450 \mathrm{~mm}$ panels showed a flatness greater than $150 \mu \mathrm{m} \mathrm{m}^{-1}$. A smaller and flatter carbon panel measuring $850 \mathrm{~mm} \times 450 \mathrm{~mm}$ has also been studied and its 3D contour plotted in figure 5(b) for comparison, with a calculated flatness of $150 \mu \mathrm{m} \mathrm{m}^{-1}$. This is the required tolerance limit. The longitudinal curvature observed on the $2450 \mathrm{~mm} \times 450 \mathrm{~mm}$ panels can thus be attributed to manufacturing faults. 

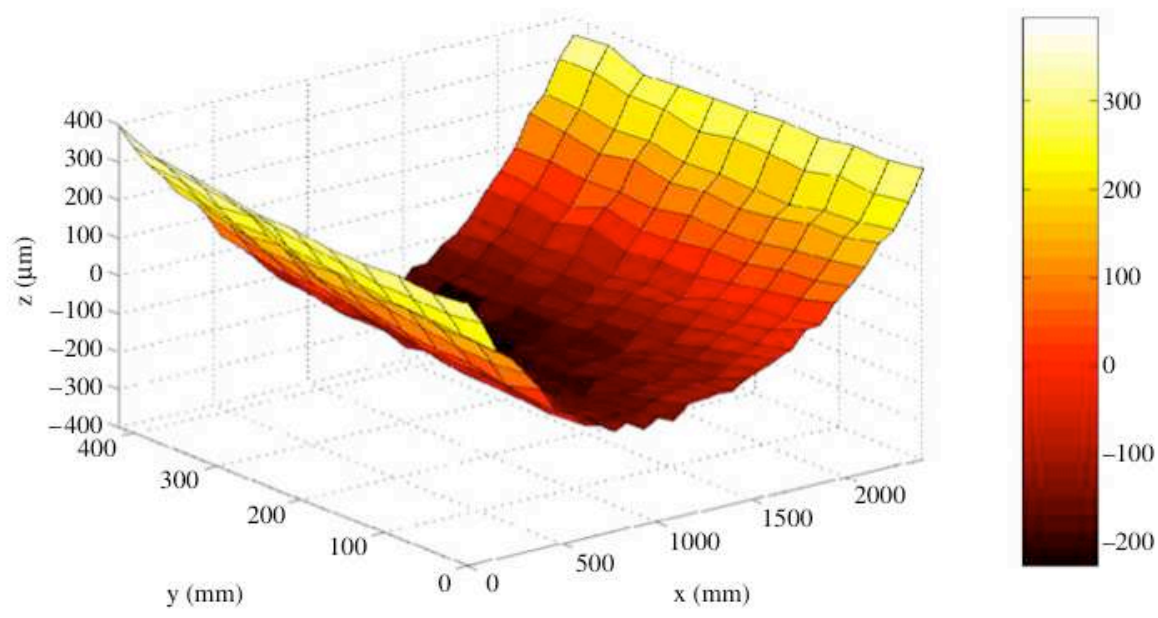

(a)

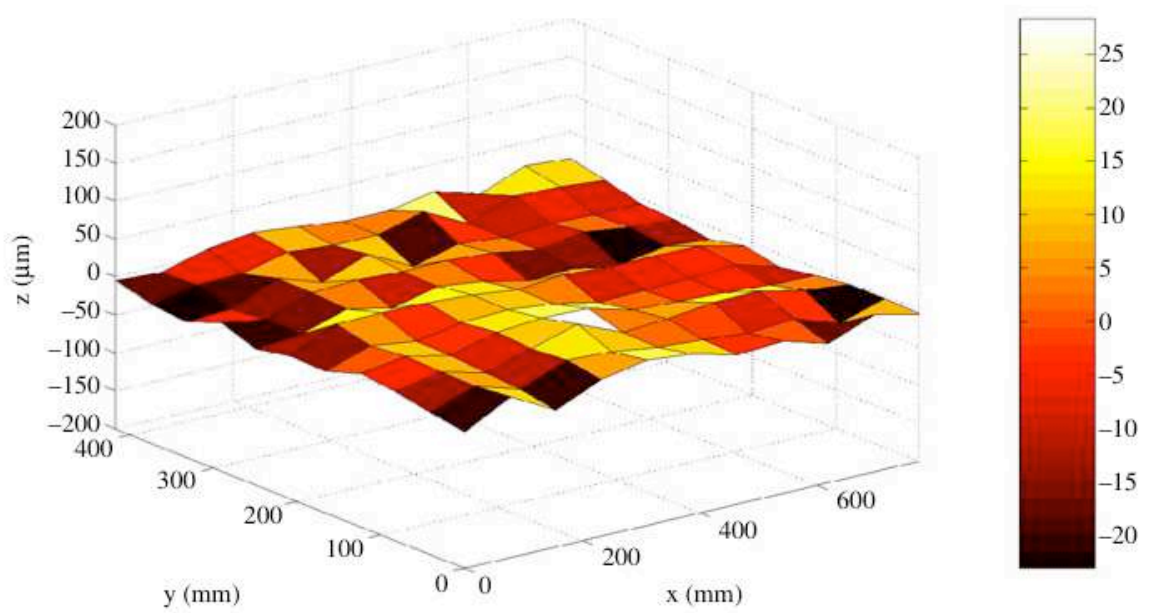

(b)

Figure 5. (a) 3D map of a $2450 \mathrm{~mm} \times 450 \mathrm{~mm}$ panel, (b) 3D map of an $850 \mathrm{~mm} \times 450 \mathrm{~mm}$ panel.

In order to determine the uncertainty of the set-up, about 10 surface profile measurements have been realized on the same $2450 \mathrm{~mm} \times 450 \mathrm{~mm}$ panel. On this panel, $11 \times$ 16 points were measured. The histogram shown in figure 6 represents the distribution of the measurement around the mean measured value. The experimental results present an uncertainty of $\pm 30 \mu \mathrm{m}$, in an interval corresponding to $95 \%$ of the measurements, which is in good accordance with the previous specifications.

A similar experiment has been carried out on a smooth surface of smaller dimensions. The distribution histogram of the measurement around the mean value is represented in figure 7. The measurement uncertainty is $\pm 8 \mu \mathrm{m}$, corresponding to $95 \%$ of the measurements.

Comparing these two results, the uncertainty of the set-up is mainly deteriorated by the slight non-reproducibility of the repositioning of $X$ and $Y$ ('re-initialization' of the mechanical fixture).

The current set-up, however, presents two other main drawbacks. Firstly, it is a time-consuming system ( $\sim 8 \mathrm{~min}$ for
100 points). Secondly, only discrete measurements are allowed at present- the finest spatial resolution, in $X$ and $Y$, which can be obtained being $0.8 \mathrm{~mm}$. It should, however, be noted that higher spatial resolution will induce longer data acquisition times. A compromise must therefore be determined taking into account these two parameters.

To avoid these drawbacks, we are currently working on a new all-optical experimental configuration using the principle of the fringe projection method. A new algorithm is being developed, enabling us to reconstruct the profile of objects. Theoretically, the algorithm may be applied for profiling objects of any arbitrary size [13].

\section{Conclusions}

We have designed a system for the measurement of any relatively flat surface profile. It allows non-contact, punctual, non-destructive measurements and can be employed on noncooperative surfaces (diffusive and black surface of the carbon 


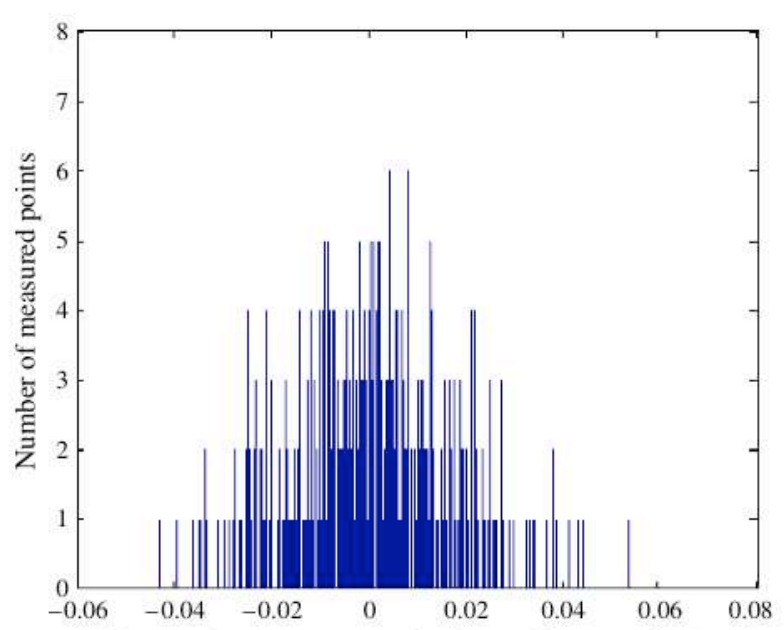

Difference between measured points and mean value $(\mathrm{mm})$

Figure 6. Distribution histogram of distance measurement on $2450 \mathrm{~mm} \times 450 \mathrm{~mm}$ carbon panel.

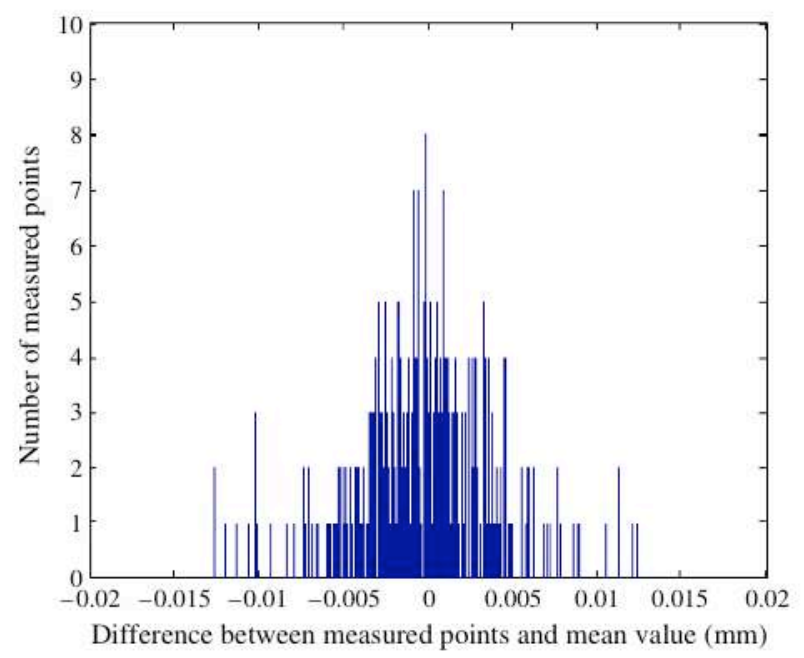

Figure 7. Distribution histogram of distance measurement on a flat surface.

panel for our application). Objects of surface areas up to $2.6 \times 0.5 \mathrm{~m}^{2}$ can be measured. The uncertainty of the setup is $\pm 30 \mu \mathrm{m}$ and the maximum deformation allowed for the panel, due to the limitation of the rangefinder, is $\pm 5 \mathrm{~mm}$. Furthermore, because of the disadvantage of the long time required, the spatial resolution must be chosen with care. The system is self-calibrated, fully automated and has a relatively low cost. This prototype can, moreover, be easily adapted to other specific needs.

\section{Acknowledgments}

The authors would like to express their thanks to E Morteau and M Canu for their assistance in the preparation and the execution of the measurements and $\mathrm{H} \mathrm{C}$ Seat for reading and correcting this paper.

\section{References}

[1] ALICE collaboration 2000 Dimuon forward spectrometer Technical Design Report CERN/LHC 2000-046 (addendum 1)

[2] Chen F, Brown G M and Song M 2000 Overview of three-dimensional shape measurement using optical methods Opt. Eng. 39 10-22

[3] Quan C, Shang H M, Tay C J and Bryanston-Cross P J 1998 Holographic contouring using double-source technique and Fourier transform analysis Opt. Lasers Eng. 30 351-62

[4] Shang H M, Hung Y Y, Luo W D and Chen F 2000 Surface profiling using shearography Opt. Eng. 39 23-31

[5] Takasaki H 1970 Moiré topography Appl. Opt. 9 1467-72

[6] Yoshizawa T 1993 Shadow moiré topography by means of the phase shift method Opt. Eng. 32 1668-74

[7] Coggrave C R and Huntley J M 2000 Optimisation of a shape measurement system based on spatial light modulators $O p t$. Eng. 39 91-8

[8] Yang H S, Kim S W and Walker D D 2003 A novel laser datum system for nanometric profilometry for large optical surfaces Opt. Express 11 624-31

[9] Chan F M M, Davis E J, King T G and Stout K J 1997 Some performance characteristics of a multi-axis touch trigger probe Meas. Sci. Technol. $8837-48$

[10] Takacs P Z, Qian S N and Colbert J 1987 Design of a long-trace surface profiler Proc. SPIE 749 59-64

[11] Huang P S and Xu X R 1999 Design of an optical probe for surface profile measurement $O p t$. Eng. 38 1223-8

[12] Aketagawa M, Takada K and Kon H 1998 Calibration of a laser reference plane for large-scale dimensional flatness measurement Meas. Sci. Technol. $91115-9$

[13] Pavageau S, Dallier R, Servagent N and Bosch T 2003 Shape measurement on large surfaces: a new algorithm, at press 